\title{
Aspectos televisuais do espiritismo na telenovela brasileira à luz dos Estudos de Cultura Visual
}

\author{
Televisual aspects of Spiritism in the Brazilian soap opera in the light of Visual \\ Culture Studies
}

\begin{abstract}
A investigação deste artigo está assentada nos modos de figuração da mediunidade em telenovelas brasileiras, exibidas nas três últimas décadas: A Viagem (1994), Alma Gêmea (2005) e Além do Tempo (2015). Valemo-nos dos Estudos de Cultura Visual e do estilo televisivo como aporte metodológico para compreender de que maneira o referido preceito do espiritismo (mediunidade) foi apresentado nas obras. O intento é captar alterações técnicas e estéticas, acompanhadas de reconfigurações socioculturais da religiosidade brasileira, num procedimento que chamamos televisualidade. Observa-se a prevalência do didatismo nas obras, apesar das singularidades adotadas, tais como a precisa referência ao espiritismo em $A$ Viagem, as inspirações doutrinárias a elementos não característicos da centralidade do espiritismo em Alma Gêmea e o teor generalista de Além do Tempo.
\end{abstract}

Palavras-chave: Espiritismo; Televisualidade; Estilo televisivo.

\section{ABSTRACT}

The investigation of this article is based on the modes of figuration of mediumship in brazilian soap operas, exhibited in the last three decades: A Viagem (1994), Alma Gêmea (2005) and Além do Tempo (2015). We use Visual Culture Studies and the television style as a methodological contribution to understand how the aforementioned precept of spiritualism (mediumship) was presented in the TV products. The intent is to capture technical and aesthetic changes, accompanied by sociocultural reconfigurations of brazilian religiosity, in a procedure we call televisuality. The prevalence of didacticism in the soap operas is observed, despite the singularities adopted, such as the precise reference to spiritualism in $A$ Viagem, the doctrinal inspirations to non-characteristic elements of the centrality of spiritualism in Alma Gêmea, and the generalist content of Além do Tempo.

Keywords: Spirtism; Televisuality; Television style.

\footnotetext{
1 Doutorando em Comunicação Social pela Universidade Federal de Minas Gerais - UFMG. Contato: marcosmeigre@ hotmail.com. Artigo recebido em 19/04/2018 e aprovado em 13/08/2018.
} 


\section{A inextrincável porosidade entre televisão e cultura}

Vislumbrada a partir do ponto de vista das artes, a televisão teve seu papel subjugado e descaracterizada enquanto meio dotado de potencial sociocultural. Martín-Barbero (2001) explica que este mal-entendido permeou os modos como os estudos de mídia encararam o meio e sua relevância no contexto latino-americano. Vista deste lugar alinhado às artes, coube à TV apenas o trágico espaço de responsável por degradar a moral e os costumes tradicionais, como instância depredadora da cultura.

Mas a perspectiva crítica de Martín-Barbero aponta em direção a outra expectativa de interpretação da mídia televisiva, principalmente no que diz respeito a formatos consagrados ao longo das últimas décadas e responsáveis por promover a simbiose entre matrizes culturais constituintes de nossas sociedades latinas com lógicas de produção e competências de consumo - como é o caso das telenovelas. O gênero telenovela se mostra capaz de "mesclar os avanços tecnológicos das mídias com as velharias e anacronismos narrativos, que fazem parte da vida cultural" da América Latina (MARTIN-BARBERO, 2004, p. 115).

Inicialmente atrelada ao rádio e ao teatro, recebendo destes a carga simbólico-dramática que conduzia suas produções, as mais recentes produções de telenovela já sofreram importantes ressignificações e sustentam-se na inovação de formatos estéticos, sem desalinharse a demandas sociais e alterações históricas, políticas culturais e religiosas do país. Lopes (2004) assegura o potencial da telenovela brasileira não apenas nos lares nacionais, mas também a boa acolhida das produções em outras nações. Esta investida transcultural, porém, não fez com que o principal produto ficcional latino-americano perdesse sua identidade.

A produção da telenovela representou, por sua vez, uma certa apropriação do gênero em cada país: sua nacionalização. Pois bem, se é certo que o gênero telenovela implica rígidos estereótipos em seu esquema dramático e fortes condicionantes em sua gramática visual reforçados pela lógica estandardizadora do mercado televisivo mundial -, também o é que cada país fez da telenovela um particular lugar de cruzamentos entre a televisão e outros campos culturais, como a literatura, o cinema, o teatro. (MARTÍN-BARBERO, REY, 2001, p. 118, grifos dos autores)

Destas concepções anteriormente levantadas, derivamos nosso entendimento de que a telenovela deve ser interpretada como um objeto dotado de complexidade organizativa, estrutural e formal, tal qual a TV como um todo. Mittell (2010) afirma que a televisão se arquiteta sob seis facetas interligadas entre si. Para o autor, a TV atua como representação cultural de uma determinada localidade; possui uma forma textual própria, que resulta em gêneros e formatos tipicamente orquestrados para o televisual; é uma instituição democrática com a pretensa intencionalidade de ser o espaço para todas as vozes, ao passo que também se configura como indústria comercial e, portanto, não se desvencilha de interesses econômicos como balizadores de sua lógica de composição; é também um meio tecnológico que permite a 
integração com outros suportes midiáticos (video-game, DVD) e, por fim, prática cotidiana que permeia as interações sociais e modos de sociabilidade dos sujeitos.

Com base nestes pressupostos, fica evidente que qualquer proposta de análise televisiva, para se tornar consistente, não deve ignorar a complexidade do meio a fim de não descaracterizar ou minimizar as potencialidades dos produtos. Por outro lado, não significa dizer que as pesquisas necessariamente contemplarão as diversas facetas constituintes da TV o que seria uma falácia, além de ser um procedimento inviável em termos metodológicos e operacionais. É preciso assumir o caráter múltiplo da televisão e, partindo deste postulado, elencar quais fatores típicos do circuito da TV serão melhor acionados em cada pesquisa específica.

Neste texto, coadunando com a perspectiva de Mittell (2010), nosso movimento de pesquisa parte do meio televisivo, entendido como prática cultural e, após a manifestação das imagens, buscamos nos processos sociais os atravessamentos capazes de sustentar o emprego dos recursos estilísticos na materialidade em questão. Em outras palavras: consumimos as imagens de modo a reconhecer os elementos externos a ela que lhe jogam importante papel em sua conformação, tais como a História, a política, a economia, as práticas religiosas, etc. Dito de outro modo: seguimos as formas textuais da TV para identificar marcas das representações culturais que lhe sustentam a organização (em especial, aqui buscamos as representações em torno do espiritismo). A televisão, enquanto meio cultural responsável por reverberar as práticas sociais, torna evidentes as mudanças processadas no âmbito da cultura. Em nossa realidade latina, é através da televisão que a maior parcela populacional acessa os costumes, apreende diretrizes cidadãs, posiciona-se em relação a demandas políticas e sociais, dentre outras questões. É, em síntese, pela TV que a modernidade nos é dada a conhecer, inserindo-nos numa gramática visual.

[...] as maiorias da América Latina estão se incorporando à, e se apropriando da, modernidade sem deixar sua cultura oral, isto é, não por meio do livro, senão a partir dos gêneros e das narrativas, das linguagens e dos saberes, da indústria e da experiência audiovisual. (MARTÍN-BARBERO, REY, 2001, p. 47)

As práticas religiosas, pela força adquirida no cenário sociocultural brasileiro, são uma das matrizes fundamentais na conformação dos enredos audiovisuais. Nesse sentido, acompanhando a evolução da doutrina espírita na composição da história nacional, este artigo investiga a figuração da mediunidade, um dos pilares do espiritismo, em três telenovelas brasileiras, veiculadas pela TV Globo: $A$ Viagem (1994, Ivani Ribeiro), Alma Gêmea (2005/2006, Walcyr Carrasco) e Além do Tempo (2015/2016, Elizabeth Jhin). Notamos a proeminência de preceitos espíritas na composição das referidas obras, de modo que temáticas como reencarnação e influências espirituais, por exemplo, foram abordadas ao longo de toda a exibição destas narrativas.

A escolha das obras levou em consideração dois aspectos principais: o primeiro deles se refere ao interesse em coletar telenovelas veiculadas nas últimas três décadas, de modo a captar possíveis reconfigurações na maneira de figurar manifestações mediúnicas; em segundo 
lugar, buscamos produções de autorias distintas, a fim de demonstrar que o debate envolvendo espiritismo se pulverizou pela escrita de diversos novelistas e não se tornou marca exclusiva de um único autor.

Neste artigo, abordamos a figuração de manifestações mediúnicas nas referidas obras para captar possíveis encaminhamentos socioculturais relacionados ao processo de difusão, aceitação e ampliação da doutrina espírita no Brasil. A projeção da doutrina espírita no cenário religioso brasileiro, numericamente, representa 3\% da população nacional (segundo dados do IBGE). Contudo, em termos de consumo audiovisual, há diversos segmentos nos quais aspectos do espiritismo se sobressaem e adquirem adesão popular. Na literatura, por exemplo, o segmento de livros espíritas mantém um mercado editorial em ascensão; no cinema, produções como Nosso Lar, Chico Xavier - o filme, As mães de Chico Xavier, Bezerra de Menezes - o filme consolidaram uma "onda espírita" na sétima arte; no teatro, peças como Violetas na Janela, Nosso Lar e Allan Kardec - um olhar para a eternidade cristalizaram atuações fundadas nas diretrizes espíritas e tiveram boa repercussão.

Já na televisão, o fenômeno da religiosidade não é recente. Todavia, é importante esclarecer que as obras escolhidas gravitam pela temática espiritualista, inspiradas em aspectos filosóficos, místicos e religiosos não exclusivos de uma única doutrina. Os críticos televisivos vêm adotando a nomenclatura "telenovela espírita" para se referir ao fenômeno das obras ficcionais baseadas nos princípios do espiritualismo, geralmente elencando obras como $A$ Viagem, Alma Gêmea, Amor Eterno Amor, Escrito nas Estrelas, Anjo de Mim, Alto Astral e Além do Tempo como as principais representantes deste que seria um novo subgênero de telenovelas. De acordo com o codificador do espiritismo, a religião se fundamenta em crenças como imortalidade da alma, reencarnação e comunicabilidade dos espíritos (KARDEC, 1997). Estes elementos estão presentes nas obras consideradas e, por esta razão, investigamos tais melodramas à luz da doutrina codificada por Allan Kardec. Para este investimento de pesquisa, seguimos pelo percurso da visualidade e o estilo televisivo como norteadores em termos de método e metodologia, respectivamente.

\section{Contribuições dos Estudos de Cultura Visual para o campo da Comunicação: ferramentas para análise televisual}

Para estudar a televisualidade de nosso objeto, convocamos autores que nos convidam a proceder sob um novo método investigativo, assentando-nos no que vem sendo chamado de Estudos Visuais. Os Estudos Visuais são entendidos como o campo de investigação, enquanto a Cultura Visual, à concepção de Mitchell (2005), seria o objeto de estudo. Neste campo, Mitchell sugere um esforço de descontaminação do olhar para que as imagens possam ser entendidas quase como seres vivos, capazes de nos dizer algo e interessadas em serem "ouvidas". Livramo-nas, assim, das amarras dos pré-julgamentos, muitas vezes estereotípicos e matizados por padronizações coletivas.

Não se trata mais de um estilo de pesquisa no campo da história das imagens, e sim de pensar nas formas pelas quais as imagens, através de interesses específicos, são produzidas, circulam e são consumidas, com o objetivo de reforçar ou resistir a articulações com os mais variados objetivos políticos, econômicos, culturais, etc. [...] Os Estudos Visuais 
questionam como e por que as práticas de ver (visualidade e visibilidade) têm transformado nosso universo de compreensão simbólica, nossas práticas de olhar, nossas maneiras de ver e fazer. (PEGORARO, 2011, p. 45)

Procede-se a um giro pictorial, sugerido por Mitchell (2009), de modo a compreender a dimensão social do visual e entender a imagem como uma realização da sociedade, intricada num processo frequente de se dar a ver para os sujeitos. Interessa-nos um investimento televisual e cultural, de modo a entender o meio em sua poética. A nosso ver, o alinhamento entre a materialidade constituinte dos objetos midiáticos e as determinações culturais auxiliam nos estudos das formas textuais - por vezes negligenciadas nas pesquisas do campo, como afirma Mittell (2010). Atentar-se às imagens antes de retê-las sob significados prédeterminados é um gesto pós-semiótico, tal qual preconiza Mitchell (2009), de modo que a materialidade em si seja considerada em primeiro plano para, daí, derivar-se os sentidos processados pelos sujeitos. É, portanto, reposicionar o papel dos indivíduos e alçar-lhes ao lugar de centralidade para a dinâmica de composição, constituição e circulação das imagens.

Televisualidade se refere aos modos como o texto televisivo evidencia questões da cultura (ROCHA, ALVES, 2014). Procede-se, neste trabalho, a uma análise televisual e a uma análise cultural: o primeiro passo é deixar as pictures, como nomeia Mitchell (2005), nos interpelarem, entender o que elas têm a dizer, sem aprisioná-las em significados dados de antemão; em segundo lugar, buscamos reconhecer e validar na dimensão social as figurações evidenciadas pela materialidade.

A potencialidade destes estudos não está em "preparar os exercícios praticantes de seus sacerdócios" (BREA, 2009, p. 05), ou seja, não buscam sistematizar modos ideais de ver e interpretar imagens, mas fomentam o crescimento do campo a partir de ponderações críticas sobre as práticas sociais. Alinhando-nos aos estudos de Cultura Visual, assumimos um novo método de apreensão das imagens que, consequentemente, nos conduz à busca de novas metodologias capazes de articular este gesto empírico de se deparar com o audiovisual. Em nosso trabalho, adotamos a concepção de Butler (2010) quanto ao estilo televisivo, entendendo-o como todo padrão técnico de imagem-som que exerça alguma função no texto de TV2. Os componentes estilísticos são cruciais para a conformação da mensagem audiovisual, dotados de significações embasadas na cultura, pois "[...] a televisão apóia-se no estilo cenário, iluminação, videografia, edição e assim por diante - para definir o tom/atmosfera, para atrair os telespectadores, para construir significados e narrativas" (ROCHA, 2014, p. 1089).

O estilo é a textura tangível do filme, a superfície perceptual com a qual nos deparamos ao escutar e olhar: é a porta de entrada para penetrarmos e nos movermos na trama, no tema, no sentimento - e tudo mais que é importante para nós (BORDWELL, 2008, pp.57-8).

\footnotetext{
2 Para maiores esclarecimentos sobre a metodologia adotada, conferir ROCHA et ali. $O$ estilo televisivo e sua pertinência para a TV como prática cultural. Insular: 2016.
} 
Butler (2010) propõe o estudo do estilo televisivo em quatro dimensões: descritiva, analítica/funcional, histórica e avaliativa. Descrever, segundo o autor, é fragmentar a materialidade audiovisual em sintagma por sintagma, valendo-se da mesma atenção e apuro que diretores, cinegrafistas, fotógrafos e outros profissionais tiveram ao elaborar a peça. A dimensão analítica/ formal diz respeito aos propósitos exercidos pelo estilo, podendo denotar, expressar, simbolizar, decorar, persuadir, saudar/interpelar, diferenciar e significar imediatismo. O estilo somente é capaz de exercer funções por buscar sustentação na conformação cultural da sociedade. Por fim, para dimensionar a evolução histórica do estilo, é preciso retroceder em programas de um mesmo gênero a fim de identificar as transformações ocorridas.

Para compor o corpus empírico, selecionamos eventos narrativos (ROCHA, ALVES, OLIVEIRA, 2013) - micro-histórias entrelaçadas ao enredo principal, compostas por início, meio e fim, podendo se estender durante alguns capítulos. Neste trabalho, coletamos pequenos eventos em que personagens estão envolvidos com questões mediúnicas, selecionados das obras aleatoriamente. Nossas análises se operacionalizaram em função das telenovelas, a fim de captar a evolução histórica da abordagem mediúnica na dramaturgia nacional, que saiu de um pedagogizante processo inicial $(A$ Viagem $)$ a uma tentativa de naturalização do fenômeno (Além do Tempo).

\section{Didatismo televisual religioso em $A$ Viagem}

Em $A$ Viagem, a sequência coletada traz uma sessão mediúnica liderada por doutor Alberto e a se desenrolar na residência do próprio médium. A reunião tem início com Alberto proferindo algumas palavras em tom de oração, numa espécie de convocação dos "amigos e orientadores do mundo espiritual" para participar da reunião. Ele está sentado numa das pontas de uma grande mesa, na qual também estão outras nove pessoas, todos de olhos fechados, mãos esticadas sobre a mesa, próximas a um copo de água para cada um dos presentes. Tanto a composição visual quanto sonora denotam uma unidade no ambiente, como se todos se encontrassem num mesmo padrão vibratório.

Esta composição cênica remete aos formatos como as reuniões mediúnicas se sucedem nas instâncias espíritas, pois Kardec (2003, p. 427) afirma que "uma reunião é um ser coletivo, cujas qualidades e propriedades são a resultante das de seus membros e formam como que um feixe. Ora, este feixe tanto mais força terá, quanto mais homogêneo for". Somente com esta pretensa unificação é possível executar um efetivo trabalho mediúnico. É desse modo que a sessão se inicia, com a compatibilidade de energias. "O início de uma sessão requer a existência de um ambiente espiritual adequado, garantido pela conduta e ação dos espíritas, pelos procedimentos rituais da fase inicial das sessões e pelo concurso de forças espirituais amigas e protetoras" (CAVALCANTI, 1983, p. 54).

Realizadas as primeiras orações, não há inserção de trilhas enquanto o doutor emite suas palavras. Contudo, tão logo ele pronuncia o nome de Alexandre (um dos personagens principais da trama, desencarnado), as captações imagéticas tornam-se escuras, sob trilha funesta, e passamos a ver um lugar sombrio, com inúmeros sujeitos se rastejando e a gritar. Este lugar é o que os espíritas definem como Umbral, um ambiente no qual se localizam os espíritos de índole inferior. O livro Nosso Lar, psicografado por Chico Xavier e que serviu de 
base doutrinária para Ivani Ribeiro (autora da novela) escrever a telenovela, tornou popular o termo ao trazer explicitações sobre a constituição desta esfera espiritual de vibrações inferiores. Enquanto Alberto ainda se pronuncia, Alexandre surge ao centro do quadro imagético e se materializa na mesa.

Os presentes permanecem de olhos fechados. Alexandre é o único que destoa dos outros integrantes em cena, com vestes escuras, em cromática oposição aos tons claros das roupas dos médiuns e também da toalha da mesa e das flores no local. Por alguns instantes, a câmera subjetiva nos concede a visão de Alexandre e o espírito rodeia o olhar pelo ambiente, captando os médiuns em primeiro plano. Alexandre está à procura de uma oportunidade para executar uma ação e, quando visualiza uma das médiuns, na cabeceira oposta a Alberto na mesa, ele esboça leve sorriso e caminha até ela. Dentre os sujeitos à mesa, apenas Alberto pronuncia qualquer declaração, mas se supõe todos sejam classificados como médiuns, atendendo à própria aclaração da doutrina, pois "[...] segundo o Espiritismo, todo homem é natural e potencialmente um médium. Não havendo, portanto, como em outros sistemas, uma hierarquia ritual evidente, não há, a princípio, intérprete humano mais qualificado do que outro" (CAVALCANTI, 1983, p. 29). Há, entretanto, níveis distintos de manifestação da mediunidade e de sensibilidades para tal, de modo que alguns sujeitos estão mais aptos a proceder a recepções de caráter mediúnico. No caso deste evento narrativo, Alberto é a personagem com este teor e devidamente gabaritado para tal.
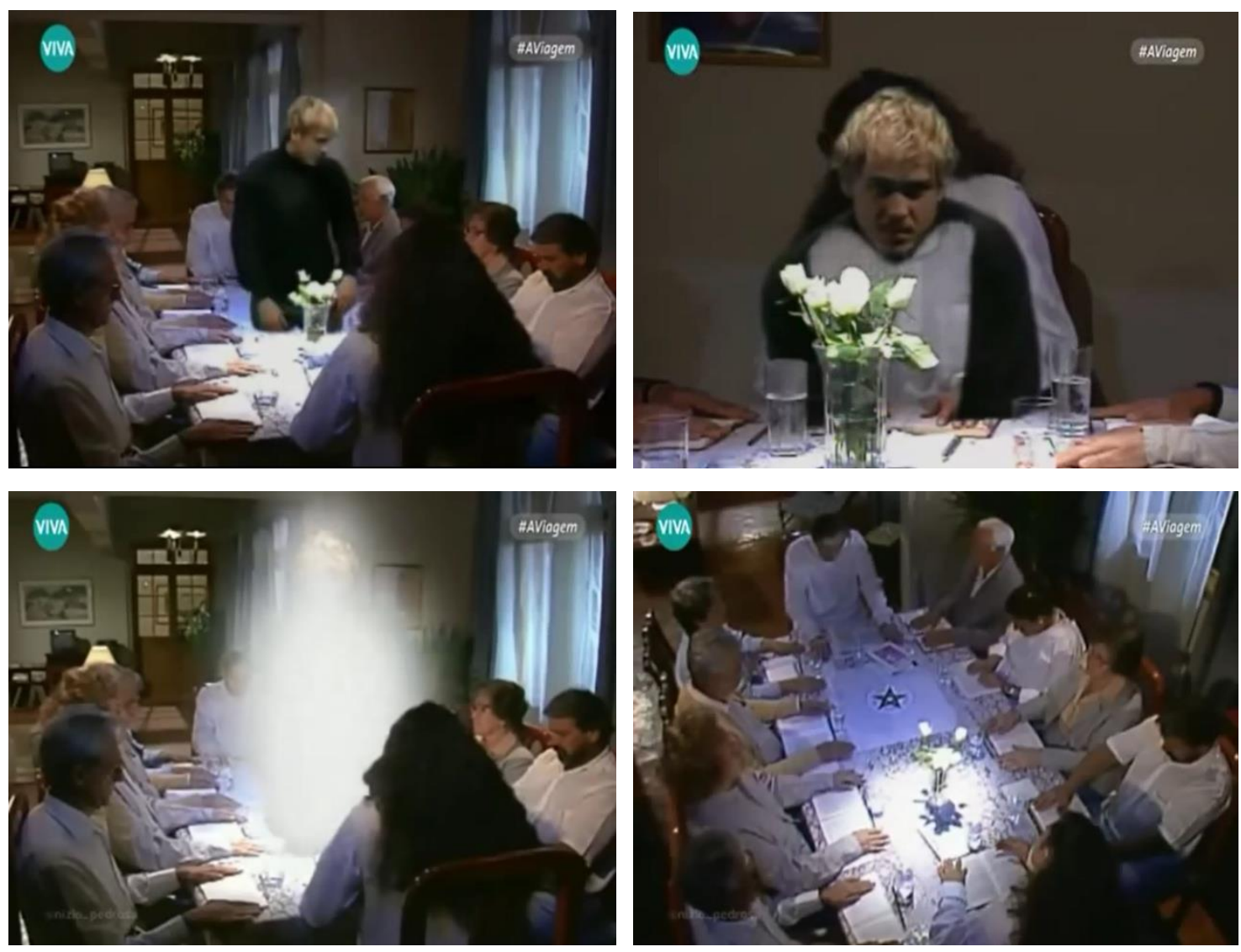

Figuras 1-4: Alexandre surge na sessão mediúnica/Fonte: Canal Viva 
A médium, personagem não identificada, incorpora o espírito de Alexandre e fica com semblante visivelmente alterado, ao que Alberto percebe as alterações e mira a mulher, declarando palavras de consolo, direcionadas ao espírito perturbado: "de coração aberto, porque todos queremos vê-lo muito feliz". A resposta é ríspida, dada pela voz de Alexandre, porém no corpo da médium. Tal ocorrência, à luz de Kardec, caracteriza os chamados médiuns falantes.

\begin{abstract}
Neles, o espírito atua sobre os órgãos da palavra, como atua sobre a mão dos médiuns escreventes. Querendo comunicar-se, o espírito se serve do órgão que se Ihe depara mais flexível no médium. A um, toma da mão; a outro, da palavra; a um terceiro, do ouvido. $\bigcirc$ médium falante geralmente se exprime sem ter consciência do que diz e muitas vezes diz coisas completamente estranhas às suas ideias habituais, aos seus conhecimentos e, até, fora do alcance de sua inteligência. Embora se ache perfeitamente acordado e em estado normal, raramente guarda lembrança do que diz. Em suma, nele, a palavra é um instrumento de que se serve o espírito, com o qual uma terceira pessoa pode comunicar-se, como pode com o auxílio de um médium audiente (KARDEC, 2003, p. 210)
\end{abstract}

Esta terceira pessoa, no caso, é Alberto, com quem Alexandre se comunica. O espírito de Alexandre caracteriza a situação como uma "palhaçada" e o tom fúnebre é intensificado pela trilha tensa. Alberto está em primeiro plano, declarando orientações espirituais, tal qual um professor diante de um aluno rebelde em classe. Alberto e Alexandre, opostos visualmente, ocupam posições diametralmente antagônicas tanto na narrativa quanto na composição cênica: Alberto é o esclarecimento, a certeza de domínio doutrinário e de orientação precisa para conduzir à evolução espiritual; Alexandre é a perturbação, a tormenta de quem não se submete às luzes do saber espiritual, ainda não convencido das postulações do mundo espiritual. Cromaticamente, neste evento narrativo, os dois personagens não estão opostos, já que Alexandre não está visível por si mesmo, mas incorporado à médium. Entretanto, outros elementos endossam a dualidade, tal como o tom de voz, que de Alexandre é grossa e grave, em teor ríspido, enquanto Alberto é mais suave e paciente em suas falas.

Após alguns momentos de diálogo com o espírito incorporado, Alberto profere um "Pai Nosso", ao que são exibidos os médiuns de olhos fechados, em primeiro plano, num travelling da câmera pelo ambiente. Encerrada a oração, o espírito abandona o corpo da mulher, vemo-nos sair do corpo da médium, postar-se ao centro da mesa e desaparecer da cena, após assumir uma forma esbranquiçada e indefinida. Com a saída do espírito do recinto, a trilha funesta também é interrompida e a paisagem sonora passa a se compor apenas pelas palavras de Alberto.

Sob um plongée da sessão mediúnica, o novo elemento sonoro é uma trilha suave, demonstrando que o ambiente já estava pacificado e sem a presença de espíritos desnorteados. Ao centro do quadro, uma roda de luz branca sobre a mesa, incidindo sobre um vaso de flores brancas. Os médiuns se dão as mãos e continuam a rezar, pedindo auxílio para espíritos "viciosos, ignorantes e sofredores", assim como pedem força para si próprios. Alberto chega a 
olhar diretamente para a câmera e deixa cair lágrimas do rosto enquanto encerra a sessão mediúnica pedindo a misericórdia divina para os necessitados.

\section{Representação visual da regressão e lembranças de vidas passadas em Alma Gêmea}

Em Alma Gêmea, a sequência considerada traz o terapeuta Julian numa sessão de regressão em Serena - a personagem principal da trama. $\bigcirc$ trecho é introduzido sob trilha tensa, enquanto Julian profere orientações para Serena, que, deitada, visualiza a chama de uma vela nas mãos do terapeuta. Enquanto o terapeuta fala, a jovem cerra os olhos e obedece a recomendação dada pelo homem: "volte no tempo". A trilha se altera e uma canção suave introduz as memórias de Serena, visualmente iniciadas por um efeito imagético similar a ondas.

A regressão é uma técnica na qual se induz um indivíduo a rememorar preceitos de existências pregressas (não se trata aqui do uso feito pela psicologia). Pelo espíritas, ela é entendida como recomendável apenas em casos de extrema perturbação. Este procedimento evoca energias intensas e, segundo Divaldo Franco3, deve ser realizada fora de uma casa espírita ou templo religioso, sob orientação enfática de um especialista da mente humana. Nesse sentido, a composição televisual em Alma Gêmea recorre às diretrizes sinalizadas pelo espiritismo. Por meio da regressão, podem ser dados a conhecer elementos de existências pretéritas dos espíritos, já que, segundo o espiritismo, "Não pode o homem, nem deve, saber tudo. [...] Sem o véu que Ihe oculta certas coisas, ficaria ofuscado, como quem, sem transição, saísse do escuro para o claro. Esquecido de seu passado ele é mais senhor de si" (KARDEC, 1997, pp. 214-215).
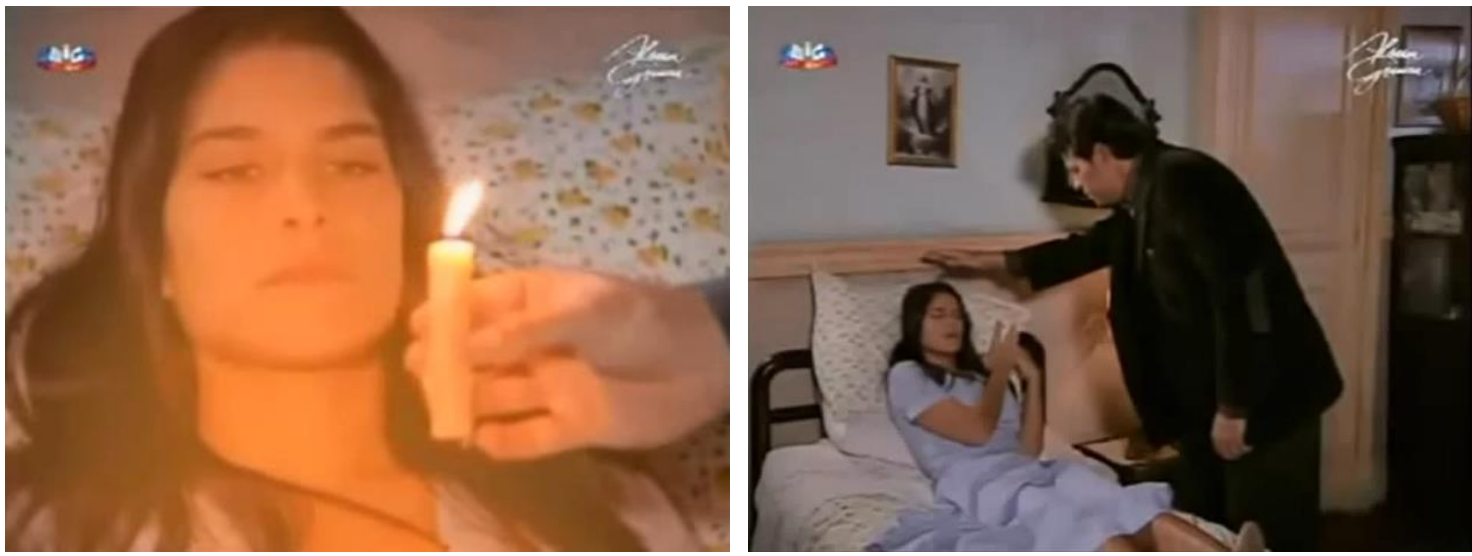

Figuras 5-6: Serena em processo de regressão/Fonte: youtube

As imagens que se sucedem exibem Luna (encarnação anterior de Serena) em seus momentos derradeiros. Há um efeito esbranquiçado em torno do quadro imagético, a fim de simbolizar a regressão sendo executada. Luna aparece ao lado do marido, da mãe, diante dos assaltantes, sendo atingida por um tiro, até que uma imagem de Serena sendo beijada a força por um homem é interposta. $\bigcirc$ homem é o mesmo que atirou em Luna. Esta revelação faz Serena se desesperar e gritar intensamente.

\footnotetext{
3 Programa Transição. Disponível em https:/ /www.youtube.com/watch?v=ee3LDGpf3Hw.
} 
Todos se assustam com os gritos de Serena e, na pensão, no salão central, os outros hóspedes se movimentam para entender as razões dos gritos. No quarto, Julian sinaliza para Serena voltar do transe, postando uma das mãos sobre a cabeça da índia a fim de acalmá-la, tal qual se procede em passes espirituais tradicionalmente aplicados em casas espíritas. Continuam os movimentos na sala entre os hóspedes até retornar à cena do quarto, com trilha tensa. $O$ terapeuta retira as mãos da cabeça da jovem, estala os dedos e Serena recobra a consciência. Serena relata o que visualizou e o terapeuta se mostra apreensivo, caminha pelo quarto, abre as cortinas, e pede para Serena ser cautelosa. Serena e Julian ainda trocam mais algumas palavras, com a moça dizendo que anseia por voltar à mata, e assim o evento descrito é encerrado.

O personagem Julian é um médium que enfrenta resistências logo que chega à pequena Roseiral, cidade fictícia onde se passa a trama de Alma Gêmea. Em termos diegéticos, a narrativa transcorre ao longo dos anos de 1940, época em que o espiritismo já dava fortes sinais como instância constitutiva do cenário religioso nacional. A esta época, importantes lideranças espíritas já eram reconhecidas - como Bezerra de Menezes - e a doutrina contava, além da Federação Espírita Brasileira (FEB) como órgão unificador dos pilares religiosos, com a publicação da revista $O$ Reformador, importante órgão da imprensa espírita nacional. Apesar destas ponderações, indicando uma proeminente condição do espiritismo no país, a religião e seus seguidores enfrentaram as perseguições policiais, eclesiásticas e até sanitárias:

O espiritismo enfrentou a oposição não apenas eclesial e religiosa como era de se esperar -, mas também a reação de vários agentes e instituições seculares, preocupados com as consequências e implicações de suas dimensões mais práticas e públicas, especialmente aquelas que incidiam sobre o campo da 'saúde pública' (GIUMBELLI, 1998, p. 132)

Tratar do espiritismo significava tratar diretamente de um debate político e também de saúde pública, pois a doutrina despertava medos e incertezas no seio social. Contudo, o modo como foi abordado na telenovela em questão, a temática não emergiu em problematizações doutrinárias e deteve-se nos aspectos melodramáticos do enredo. Dessa maneira, o evento narrativo considerado demonstrou que a telenovela valeu-se de instruções espíritas sem, no entanto, limitar-se a elas.

\section{A abordagem de Além do Tempo quanto às memórias de outras existências}

Em Além do Tempo, Gema e Mateus não são personagens do eixo central da narrativa, mas o jovem tem um dom especial e busca, com a ajuda da mãe, esclarecimentos sobre as visões e sensações que o acompanham. Eles vão até a casa de Elias, um mestre em conhecimentos espiritualistas. Elias os recebe numa casa simples, de madeira. Enquanto adentram ao imóvel, a trilha é suave e a câmera realiza um zoom out até que tomemos conhecimento de boa parte do interior da casa. Há muitos livros, algumas plantas e adereços, mas nada que caracterize o local com uma aura religiosa ou mística, tampouco instrumentos, vestimentas ou itens ritualísticos para o momento da conversa entre os envolvidos.

A conversa entre eles é entremeada de primeiros planos, com cortes elementares no esquema plano/contraplano enquanto o mestre chega a revelar detalhes do pensamento de Gema durante o encontro. Mestre orienta Gema a relaxar, desligar-se de preocupações 
rotineiras e concentrar-se naquele momento de serenidade. No instante seguinte, mestre Elias pede a Mateus para ver os desenhos e o plano geral que os enquadrava dá vez a um primeiro plano de uma das obras do garoto, às mãos de Elias. $O$ mestre analisa as peças e profere esclarecimentos aos dois a sua frente: relata que a mente humana está envolta em cargas de mistérios, questões impossíveis de se conceber em nosso atual estágio evolutivo. Em termos audiovisuais, a trilha permanece serena, coadunando com a aura de pacifismo do ambiente. Quanto aos enquadramentos e planos, o esquema de primeiros planos, intercalados no jogo plano/ contraplano, permanece usado à exaustão até o encerramento do trecho.
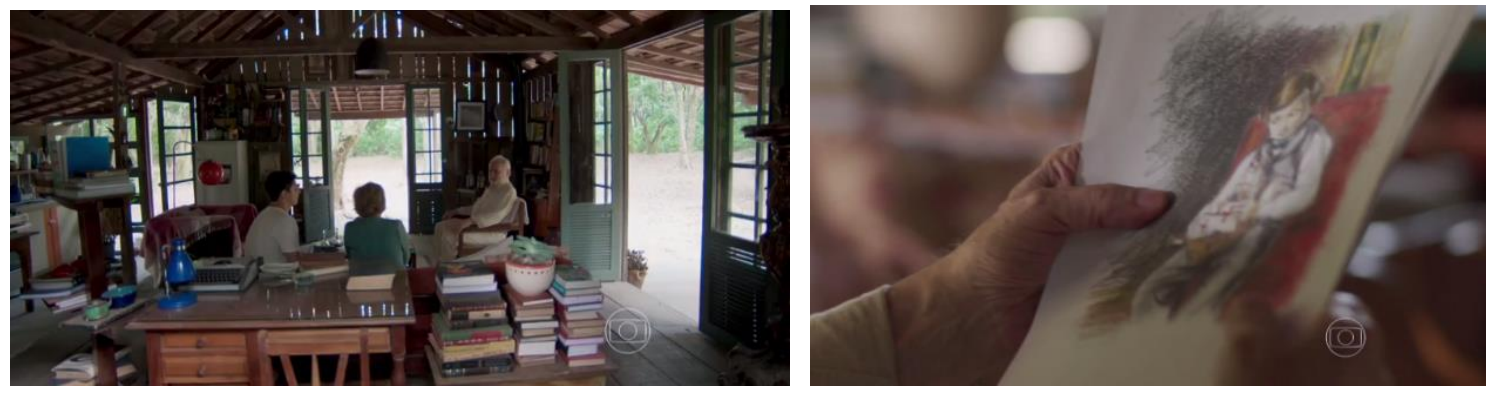

Figuras 7-8: A casa de Elias e os desenhos de Mateus/Fonte: Gshow

Nesta obra, portanto, não há qualquer sinalização evidente de aparição de espíritos ou elementos mediúnicos nítidos. $\bigcirc$ que se tem, neste caso, é a exibição de impressões e conversas sobre espiritualidade, existencialismo, superioridade moral, vivência cristã, etc. A dimensão da mediunidade é aqui trabalhada ao exemplificar a psicopictografia - habilidade de produzir desenhos e pinturas em situação de influência mediúnica. Assim sendo, a obra não se sustenta em termos didaticamente espíritas para tratar da mediunidade do jovem desenhista, mas tenta apenas introduzir o assunto de maneira generalista e sem problematizações, como se quisesse naturalizar o debate em torno do tema ao transportá-lo para uma conversa cotidiana e aparentemente banal na sala de uma casa. Lentamente, o jovem vai sendo apresentado à concepção doutrinária quanto a existência de vidas anteriores, sem, no entanto, ser surpreendido com instruções de teor espiritualista. $\bigcirc$ mestre, por exemplo, profere exclamações vagas (como "Há mais mistérios entre o céu e a terra do que podemos imaginar") e, atrelando-se este procedimento aos aspectos socioculturais, é possível ponderar que a telenovela não pretendeu causar qualquer tipo de impacto ao adotar esta abordagem, sem tornar evidente uma doutrina religiosa específica e, assim, evitar fugas de espectadores não alinhados a tais correntes.

A maneira de figuração da mediunidade em Além do Tempo pode ser resultado de demandas oriundas das lógicas de produção e também das competências de consumo, tais como desenvolvidas por Martín-Barbero (2001). Dadas as novas potencialidades técnológicas agregadas ao meio e a consequente configuração de novas sensibilidades atreladas ao ver, "o mercado está reclamando a mobilização de processos de experimentação e inovação que permitam inserir nas linguagens de uma tecnicidade mundializada a diversidade de narrativas, gestualidades e imaginários nos quais se expressa a verdadeira riqueza de nossos povos" (MARTIN-BARBERO; REY, 2004, p. 119). Para tratar de nossa riqueza religiosa, a referida 
telenovela caminhou por uma vertente mais generalista e, assim, confortável em termos de composição das representações em cena.

\section{Considerações finais}

Estudar televisão implica reconhecer as especificidades culturais de uma determinada região, país ou área. Os modos de organização do meio são intrinsecamente perpassados por mediações culturais a orientar as lógicas de produção e circulação das televisualidades. "[...] cada país tem sua televisão, que implica variáveis distintas de análise, mais complexas do que as que se observam no cinema, por exemplo. Na televisão, os campos do conteúdo, da estética e da política são indissociáveis de suas características específicas, como: a grade; as possibilidades tecnológicas; a competitividade entre os diversos canais e suas características específicas [...] (MUANIS, 2015, p. 91)". As expressões religiosas compõem o panorama das mediações constituintes de uma sociedade e, no caso brasileiro, o espiritismo tem alçado relevância na cena dos debates públicos. Por isso, julgamos que tal religiosidade - de notória visibilidade no país - demanda análises sobre seus modos de aparição midiática.

O didatismo religioso permeou as narrativas audiovisuais consideradas para esta análise. A passagem das décadas não eliminou a necessidade de se valer das orientações e explicações, em maior ou menor medida, para explicitar aspectos do espiritualismo. Ao que se notou, as primeiras obras alicerçaram-se com maior ênfase no didatismo, possivelmente como modo de desbravar a temática. $A$ Viagem foi a obra mais didática e balizada sob rígida proximidade com os ensinamentos espíritas. Alma Gêmea, por sua vez, recorre ao espiritismo para tratar da mediunidade e de vidas passadas sem, no entanto, ferir princípios doutrinários. Já Além do Tempo apresenta caráter explicitamente generalista, distanciando-se de demarcações religiosas no momento de figurar preceitos da mediunidade. Nesse sentido, parece ser, em alguma medida, a que mais se tangencia às declarações de Kardec, que afirma todos os sujeitos serem médiuns, suscetíveis a ações e interferências espirituais. Tal obra, em alguma medida, naturaliza esta consideração e tenta cotidianizar o conceito da mediunidade - ao contrário das anteriores, que singularizavam os momentos em que tal fenômeno ocorria.

Apesar das distinções entre as obras, é possível elencar elementos unificadores. Por exemplo, em todos os casos, há sujeitos em situação de vulnerabilidade emocional - sejam eles encarnados ou desencarnados: o espírito de Alexandre ( $A$ Viagem) está transtornado no Umbral e vai até a sessão mediúnica; Serena ( $A$ Ima Gêmea) se inquieta, grita e se assusta com as visões da vida passada; Mateus (Além do Tempo) está confuso e intrigado com o dom espiritual que possui. Personagens em condição de instabilidade que entram em contato com figuras de preparo psicológico e instrucional, atuando tais quais professores a ensinar e esclarecer as diretrizes atreladas ao místico, ao transcendental que lhes escapa ao entendimento. Os médiuns/orientadores assumem a posição de equilíbrio, de seres em estágio superior da evolução, capazes de orientar os que porventura estejam em perturbação.

Enquanto $A$ Viagem e Alma Gêmea trouxeram encenações mais efusivas, com atuações notoriamente exaltadas para figurar a evocação de espíritos desencarnados e a rememoração de existências pregressas, Além do Tempo enfatizou na serenidade, no tom de voz ameno, nas trocas de olhares a possibilidade de entendimento quanto ao espiritual. Nesse sentido, a novela 
de Jhin se diferenciou por adotar um teor em que a moderação e o diálogo são reveladores das práticas em questão: conhecer, entender o místico não requer atuações carregadas de gritos ou exaltações, mas o fato de se inserir em ambientes harmoniosos e se valer de conversas e orientações com líderes espirituais permitiria a obtenção de esclarecimentos.

Em nenhuma das sequências consideradas há citações ou referências a centros espíritas diretamente, de modo que os ambientes cênicos são - sem exceção - casas comuns onde vivem os referidos personagens. Não há citações ao espiritismo, tampouco a Chico Xavier (liderança mediúnica espírita, consagrada internacionalmente), mas as influências doutrinárias são captáveis nas ocorrências cênicas.

Os médiuns são pessoas instruídas religiosamente, dotadas de saberes referendados pela doutrina, muitas das vezes apropriando-se de conceituações cientificistas para validar suas atividades doutrinárias. Valer-se de explicitações didáticas num dos formatos mais consagrados da televisão nacional, a telenovela, pode ser uma maneira de argumentação defensiva do espiritismo no cenário sociocultural brasileiro. Desde os primórdios marcada por perseguições e pela necessidade de se fazer validada como instância religiosa sólida, a doutrina espírita encontrou na teledramaturgia um caminho capaz de referendar seus preceitos, legitimar seus discursos e popularizar suas práticas. Por meio de análises televisuais, podemos compreender estas alterações para entender que elementos estilísticos (como foram as trilhas e cenografia nestas obras) e aspectos socioculturais atuam concomitantemente, aliados, e conformam as imagens que consumimos, carregadas de sentidos acerca do espiritismo.

\section{Referências}

BORDWELL, David. Figuras traçadas na Iuz. a encenação no cinema. Trad. Maria Luiza Machado Jatobá. Campinas: Papirus, 2008.

BREA, José Luis. Los estudios visuales. por una epistemología política de la visualidad. Centro de Estudios Visuales de Chile, Señas y Reseñas, 2009.

BUTLER, Jeremy. Television Style. New York: Routledge, 2010.

CAVALCANTI, Maria Laura Viveiros de Castro. O mundo invisível. cosmologia, sistema ritual e noção de pessoa no espiritismo. Rio de Janeiro: Zahar, 1983.

GIUMBELLI, Emerson. Caridade, assistência social, política e cidadania: práticas e reflexões no espiritismo. In: LANDIM, Leilah (org.). Ações em Sociedade - militância, caridade, assistência, etc. Rio de Janeiro: ISER/NAU, 1998.

KARDEC, Allan. O livro dos espíritos. Trad. Guillon Ribeiro. 77ª ed. Brasília: FEB, 1997.

KARDEC, Allan. O livro dos médiuns. Trad. Guillon Ribeiro. 71ª ed. Rio de Janeiro: FEB, 2003. 
LOPES, Maria Immacolata Vassalo de. (org). Telenovela. Internacionalização e interculturalidade. São Paulo: Edições Loyola, 2004.

MARTIN-BARBERO, Jesús; REY, Germán. Os exercícios do ver. hegemonia audiovisual e ficção televisiva. Trad. Jacob Gorender. São Paulo: Editora Senac São Paulo, 2001.

MITCHELL, W. J. T. What do pictures "really" want? Chicago: The University of Chicago Press, 2005.

MITCHELL, W.J.T. Teoría de la imagerr. ensayos sobre representación verbal y visual. Trad. Yaiza Hernández Velázquez. Madri: Ediciones Akal, 2009.

MITTELL, Jason. Television and American Culture. New York: Oxford University Press, 2010.

MUANIS, Felipe de Castro. A pior televisão é melhor que nenhuma televisão. MATRIZes (online), v.9, p. 87-101, 2015.

PEGORARO, Éverly. Estudos Visuais: principais autores e questionamentos de um campo emergente. Revista Domínios da Imagem, Londrina, ano IV, nº 8, p. 41-52, maio 2011.

ROCHA, Simone M.; ALVES, Matheus Luiz Couto; OLIVEIRA, Lívia Fernandes de. A História através do estilo televisivo: a Revolta da Vacina na telenovela Lado a Lado. Revista Eco-Pós (Online), v 16, 2013.

ROCHA, Simone M. O estilo televisivo e sua pertinência para a TV como prática cultural. Revista Famecos, v 21, n 03, 2014. 